\title{
POTENTIAL ERRORS IN FORENSIC MEDICINE PRACTICE: CASE REPORTS AND LITERATURE REVIEW
}

\author{
Ragaa Mohamed Abd-Elmaaboud ${ }^{1}$, Ghada Ali Omran ${ }^{1^{*}}$ \\ Forensic Medicine and Clinical Toxicology Department, Faculty of Medicine, Assiut University, \\ Assiut, Egypt
}

\begin{abstract}
In Egypt, the Forensic Medicine profession is a multidisciplinary medical specialty that mainly deals with the examination of deceased persons suspected to have been injured or killed by external influence such as trauma or intoxication. In addition, clinical forensic medicine deals with living persons with violent injuries either intentional or accidental like those resulting from medical errors, sexual assaults or age determination. The forensic medical examiner may be confronted with challenging cases of burned, decomposed, or dismembered bodies. Although the legislation regarding forensic pathology differs between countries, a universal principle is that in the investigation of a possible or suspected criminal death, a forensic examiner is engaged through a formal request from the police or the prosecutor as a medical expert for justice. However, unlike many other medical specialties, malpractice in forensic medicine profession is an issue seldom presented in literature worldwide. The current study aim was to shed lights on some cases as different examples of potential forensic malpractice in Egypt. The five cases discussed indicated that there are several unique features of errors in the performance of medico-legal autopsies beside systematic legal errors that can all distort investigation outcome or interpretation with subsequent unjust sentences or decisions. Those task-specific errors need to be tackled by adopting efficient and different training and qualification policies alongside supporting legislation and financial aids for funding additional complementary facilities.
\end{abstract}

Keywords: Forensic, malpractice, errors, cases, Egypt.

*Corresponding author: Ghada A. Omran ; Department of Forensic Medicine and Clinical Toxicology, Faculty of Medicine, Assiut University, Assiut governorate, Egypt; Tel: ++2 0882413592; E-mail: ghada_ali@hotmail.com; ghada.omran@aun.edu.eg

\section{INTRODUCTION}

F orensic medicine is a large medical specialty encompassing multiple subdisciplines mainly forensic pathology, clinical forensic medicine, forensic anthropology and odontology (Pinheiro, 2006). Forensic pathology deals mostly with examination of deceased persons suspected to have been injured or killed by external influence such as trauma, occupational hazards, intoxication or even medical errors. The forensic pathologist functioning as a medical examiner has the further duty to certify the death in law, making official (and often public) record of their determinations (Matshes et al., 2011). Meanwhile, clinical forensic medicine is concerned with cases of any act of violence on living subjects, sexual assaults and age estimation (DiMaio and DiMaio, 2001). In developed countries with sophisticated medicolegal systems, such autopsies will be performed only by forensic pathologists with considerable experience, but in many areas of the world -especially the developing countries- lack of adequate personnel and resources as well as considerations of distance and facilities, mean that almost any doctor may be called upon to perform medicolegal examinations (Saukko and Knight, 2015). Though medical conventions and legal systems vary considerably from country to country, there are generally two main types of autopsy: The clinical or academic autopsy and the medico-legal or forensic autopsy, which is the only type performed on suspected unnatural deaths under the instructions of the legal authority in Egypt.

The Egyptian medicolegal authority is responsible for conducting death investigations and certifying the cause and manner of unnatural and unexplained deaths. This is performed through recruiting faculties 
of medicine fresh graduates without forensic experience as a prerequisite. Those physicians should deal with fatalities including homicides, suicides, unintentional injuries, and drug-related deaths. Additionally, clinical forensic medicine section is concerned with living subjects with suspected criminal injuries, cases of impotence for divorce, sexual assaults, medical responsibilities, paternity and family relationship testing and permanent infirmities evaluations as a result of criminal violent acts. Forensic toxicology, histopathology, serology and forensic genetics laboratories are complementary technical facilities implemented to assist the forensic examiner to reach overall conclusion reported in the final report. The Egyptian medicolegal system is somewhat similar to one of the most comprehensive medicolegal organization worldwide which is the Portuguese medicolegal system (Pinheiro, 2006).

\section{Medicolegal autopsy objectives}

The main classic goals of carrying out forensic autopsy are to determine the manner and cause of death in addition to identification of victims for personal, ethnic and genocide related issues that imerged as concerns recently. The cause of death can be natural or unnatural (violent) or could be undetermined. If the case matches a violent death, three possibilities arise mainly as traumatic injuries, asphyxia, or intoxication. Then, traumatic wounds should be classified according to the instrument or weapon used either blunt or sharp, or a mix. Other subsidiary goals of an autopsy are to establish the time of death when possible (Saukko and knight, 2004; Pinheiro, 2006), to describe internal and external injuries within full medicolegal reports including interpretation of findings and concluding remarks. Relating recorded injuries to a specific event notified through the police or parquet and collecting appropriate samples for histopathology, toxicology, serology or even genetic testing, are mandatory in most cases to complement information gained from the macroscopic appearance of injuries or other diseases (Vernard, 2002; Pinheiro, 2006). Other contributing factors to death should be looked for as well. In Egyptian medicolegal system, the firearm associated deaths or injuries; besides of determining the time, cause and manner of death, it is essential to know the type of weapon used the distance and direction of firing.

\section{Potential forensic medicine malpractice}

Several unique features are peculiar to errors performed by forensic medicine practitioners worldwide even if they are competent enough. Unfortunately, those errors might have disastrous consequences on the litigation process. Dr. Alan Moritz, who was a professor of pathology had published a milestone paper describing most classical medicolegal errors in 1956, that was republished in 1981(Moritz, 1981; Matshes et al., 2011). To the author's knowledge, the research articles specifying forensic malpractice were scarce thereafter. However, from the authors' point of view, the recorded and expected errors in medicolegal practice can be summarized to fall into two main categories; either profession related or technical errors and medicolegal systemrelated errors.

\section{a) Forensic medicine profession related (technical) errors}

The forensic medicine practitioner may be unaware or has limited knowledge regarding the main objectives of medicolegal autopsy mentioned earlier, or performing an incomplete or premature termination of autopsy (Matshes et al., 2011). Additionally, inadequate examination of decomposed or mutilated bodies due to odor or insects with failure to identify the body and losing valuable information related to cause and manner of death are also reported. Nonrecognition of postmortem changes with subsequent erroneous conclusions may also be encountered along with failing to describe any external abnormalities on the skin or the clothing. It is also unsuitable to find statement of opinions or interpretation in the objective part of the report thus confusing the subjective section of the protocol with the objective part. Using none scientifically proven interpretations are also unacceptable in conjunction with inadequate taking or proper handling of specimens for laboratory investigations (toxicological, genetic and/or histopathologic) (Mortitz, 1981; Vernard, 2002). Some forensic practioners argue that 
their role is guided mostly by their statutory obligation to determine cause and manner of death. None of them would pay attention to documenting other information that does not necessarily contribute to the determination of death mechanism, but they may provide additional data of great value to law enforcement and the criminal justice system. This is just like a shoe imprint on the back of a person shot in the head, or collection of specimens as part of a sexual assault investigation (Matshes et al, 2011).

\section{b) Medicolegal system related errors}

In some localities with differentiated medicolegal systems, examination of the scene of the crime by the forensic pathologist is not feasible; however, it is mandatory in most cases. Pathologists who do not examine the site where the body was found must rely on the written or oral reports of the circumstances of death, and photographs or illustrating sketches, if they are available (Adams and Krutsinger, 2000). The significance of autopsy of a case of unexplained violence, for instance, maybe only obtained through scene examination before moving of the body. The postmortem changes may be only appreciated if seen by the forensic medically trained person. Furthermore, photography is of paramount importance to document the scene evidence and the cadaver status before any disturbance or transfer of the body to the morgue for autopsy. Additionally ignoring or lack of well-equipped facilities for autopsy with enabled radiological investigations especially in cases of advanced putrefaction along with the shortage of resources as a proper chain of custody for transfer body tissue or fluid samples, usually compromise the opinion or interpretation reached during death investigations (Moritz, 1981).

\section{CASE REPORTS}

Data was collected from selected cases chosen by the first author during private medicolegal consultation work in the period from 2012 through 2018. The study focuses on potential errors committed by the forensic practitioners concerning postmortem autopsy related technical errors (Case 1, 2 and 3), medical responsibility evaluation related error (Case 4), and permanent infirmities evaluation associated error (Case5). Ethical approval has been obtained in accordance to the faculty of Medicine, Assiut University ethical committee guidelines. To secure confidentiality, personal information of the primary medicolegal examiner or cases participants, addresses or specific region, and the dates of the case events were removed.

\section{Case (1)}

The case was notified to the police as a homicide of a fifth-decade male farmer living in a small village in Upper Egypt. Two witnesses (victim's nephew and brother) testified that he was attacked by his neighbors who shoot him during a quarrel inside the victim's house. The distance of firing was markedly discrepant among the two witnesses testimony, where one said that it was from 2 $\mathrm{cm}$ and the other said that it was one and a half meters. Crime Scene examination revealed the presence of local handmade country gun beside the victim. The body was found in a pool of blood, and another pool was far away with parallel streaks in between. There were signs of a blood stain cleanup on the internal surface of the house door before the arrival of law enforcement agents. The forensic practitioner reported a large inlet wound with lacerated edges, measuring 4x6 $\mathrm{cm}$ on the anterolateral part of the right thigh just below the iliac crest by $4 \mathrm{~cm}$ with the absence of powder marks or shots dispersion around the wound. The exit wound was $5 \times 7$ $\mathrm{cm}$ in the internal aspect of the thigh to the right of the scrotum with massive laceration of the right femoral artery and vein. The internal wad and some spherical shots were extracted from the inlet wound. Clothes examination revealed coinciding loss of substance matched with the inlet without signs of near firing. The forensic practitioner concluded that the victim was shot from right to left direction with a bore 16 shotgun cartridge from a distance of 2 meters for long weapons and half of this for short ones. He added that this pattern of injury could be consistent with what was stated by the two eyewitnesses.

\section{Case (2)}

A body of a man in the third decade of age was found on the River Nile shoreline in a village belonging to an Upper Egyptian 
governorate. His clothes did not contain any identifying papers. When the father of the deceased, was questioned (he previously notified the police with his missing son (Figure 1) of the same age of recovered body), he decided that the deceased was his son. He also added that the son was always absent from home and was suffering from mental disease and that he did not accuse anyone of his death. The forensic examiner reported that the unknown corpse was in a stage of advanced putrefaction, greenish discoloration and swelling of the body; the skin was peeled off in some parts with cutis anserina of hands and feet. A bloody froth was coming out the nose and mouth, and the lips were cracked like a congenital defect similar to what is called cleft (hare) lip. No other antemortem injuries were observed externally. On autopsy, head, neck, and chest were devoid of fractures, injuries, diseases or hemorrhage but the only findings were sand detected inside the trachea and pleural effusion with congestion of lungs. He concluded that the cause of death could be drowning that led to marked hypotension and respiratory failure. Toxicological examination of internal organs proved negative for any sedative, hypnotics or drugs of abuse.

\section{Case (3)}

A cadaver of an unknown person was found packed in a plastic bag, beside an irrigation machine in a village in Upper Egypt. The residents of the village identified the body. The victim was a 45 years old farmer who was married to a 38 years old woman. That wife was known of her forbidden sexual behavior through dating strange men for an amount of paid money. There was a serious conflict between that wife and her husband, which led to her thinking of getting rid of him in agreement with three men of her friends. When the accused persons were asked about the details of the crime, one of them stated that the husband was sleeping on the ground in one of the house's rooms, one of the accompanying accused men gave several blows to his head with a chopper until he died. The victim did not resist the defendant because he was drug hypnotized by his accused wife. The defendant and other accused men wrapped the deceased husband in a bed sheet and put him in a plastic bag to be disposed of by aid from another allying driver. The wife denied that she was planning to kill her husband, and she called one of them the night of husband's killing, to have sex with him but he came with one of his friends. During their conflict, her husband woke up; he had a quarrel with them that led to his killing after two blows on head and dorsum of his hand by one of the two friends. The police officer described the bloodstain distribution pattern at the crime scene (Figure 2) as some bloodstains at the top of the wall to the right of the interior of the room and the bottom of the wall to the left. A large pool of blood was found on the carpet with the absence of clear blood spots on the bed but only suspected bloody traces on the pillows. Accordingly, he concluded that the accused persons with a chopper attacked the husband in his bed while he was under the effect of the hypnotic drug given to him by his wife. The forensic examination of the victim revealed multiple deep cut wounds in the anterior, sides and back of the head. Also, there were multiple deep cut wounds on the back of right shoulder, the back of the right and left forearms and wrists (Figure 3). The forensic examiner concluded that those findings matched the police investigations, but he did not order for any appropriate toxicological analyses to prove or negate the alleged statements regarding drug-induced hypnosis of the victim before being killed.

\section{Case (4)}

A malpractice claim was raised against an anesthetist on a request of a man three years after a hemorrhoidectomy operation with spinal anesthesia. He reported that after two months from a hemorrhoidectomy operation, he complained of low back pain that necessitated orthopedic surgical intervention later on after failure of treatment with broadspectrum antibiotics. Before the orthopedic surgical intervention, a sample of the lumbar spines was taken and sent for histopathological analysis. The issued report revealed the presence of acute purulent infection with necrosis between the third, fourth and fifth lumbar spaces that were also confirmed through a magnetic resonance imaging which added the presence of an 
extradural abscess. Two conflicting reports were issued by the orthopedic surgeon who operated. One stated that the patient suffered from only necrosis in lumbar vertebrae and the other report specified tuberculosis in the affected vertebrae. He was prescribed antituberculous drugs for a year, as he did not respond to any other antibiotics and underwent the diskectomy surgery with bone graft resulting in complete recovery. The medical reports issued by the accused surgeon and the anesthetist that the hemorrhoidectomy operation was carried out in accordance of "standard of care" through preoperative fitness clinical and laboratory evaluation, spinal anesthesia using a disposable sterile needle and proper skin sterilization. The patient recovered adequately postoperative and discharged after two days. Three years after the hemorrhoidectomy and orthopedic operations, the patient raised the malpractice issue. The forensic examiner did not find the patient suffering from any a surgical hernia or signs of neurological illness or signs of pulmonary tuberculosis. He requested an expert opinion of orthopedic and chest diseases consultants who found a negative sputum sample for tuberculosis. Noteworthy, the case was not reviewed by an expert in the relevant specialty (anesthesia). Additionally, he concluded that what happened to the patient was a result of contamination of the injection site during anesthesia due to the use of non-sterile tools and this was a grave mistake of the anesthetist that led to bone tuberculosis with subsequent complications that necessitated another orthopedic operation. The anesthetist was claimed of severe negligence for compensation. The result was payments to the plaintiff.

Case (5)

A farmer decided that, while he was working on irrigation of his agricultural land, he was surprised that three brothers of his neighbors attacked him in multiple parts of his body with thick sticks. Medical reports described his injuries as comminuted fractures of the left ulna and fissure fracture of the fifth right metacarpal bones in addition to multiple abrasions, bruises, and lacerations on many areas of his body. He was referred to the hospital and underwent an open surgery to fix fractures by plate and screws in the left forearm and under elbow splint and cast for right hand fracture. Five days later, he was discharged and continued treatment outside the hospital. His wounds were cured, but he cannot naturally move his left arm and cannot do his work in cultivating his land. He felt pain and restriction of movement in the fingers of his right hand, in addition to pain in the thigh where a bone was taken (a bone graft from pelvic bones) to fix the comminuted fracture in his left forearm. The forensic medical examiner reviewed the medical reports and associated $\mathrm{x}$ - rays of the left forearm (Figure 4a), and the right hand bones (Figure 4b). He decided that the victim not deserve any compensation for his acquired infirmity and considered the case as ordinary unhealed fracture with no resulting infirmity.

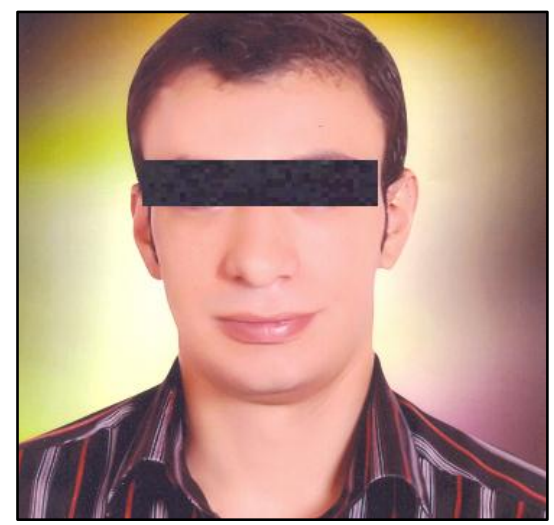

Figure 1: An antemortem photo of the deceased person (case 2) whose dead body was found in advanced state of putrefaction, showing wrongful post mortem diagnosis of cleft lip(hare lip). 


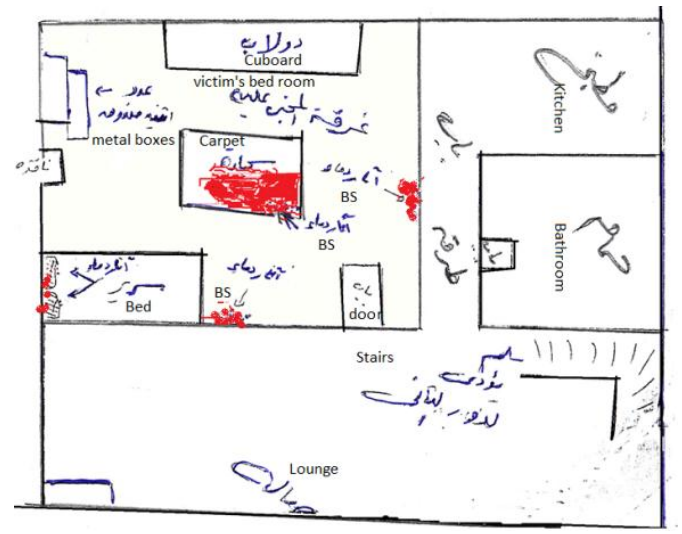

Figure 2: Crime scene schematic diagram illustrating victim's house layout and blood stain patterns of case (3).*BS: blood stains in red.

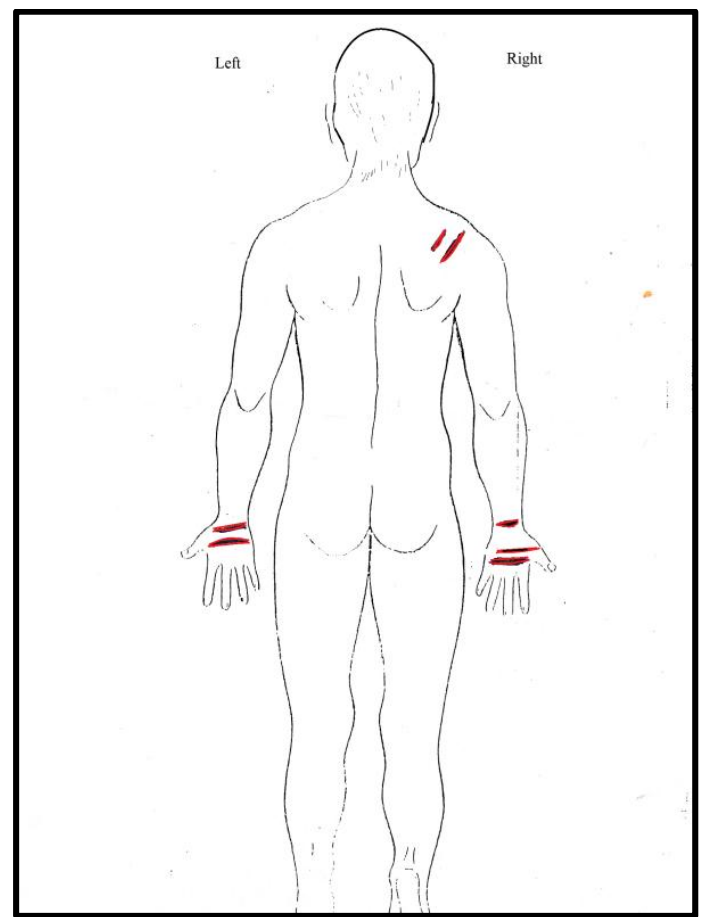

(a)

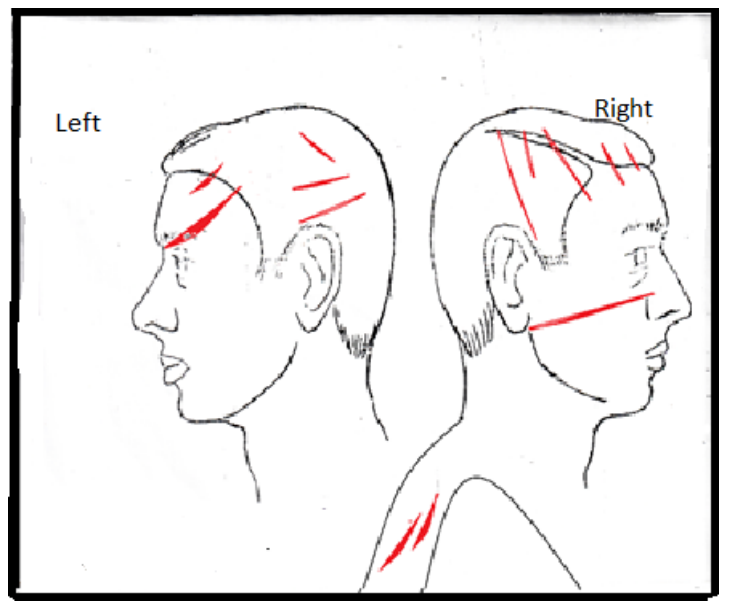

(b)

Figure 3: Distribution of wounds with sharp edges on dorsum of the shoulder and both hands (a) alongside head and face (b) in victim of case (3). 


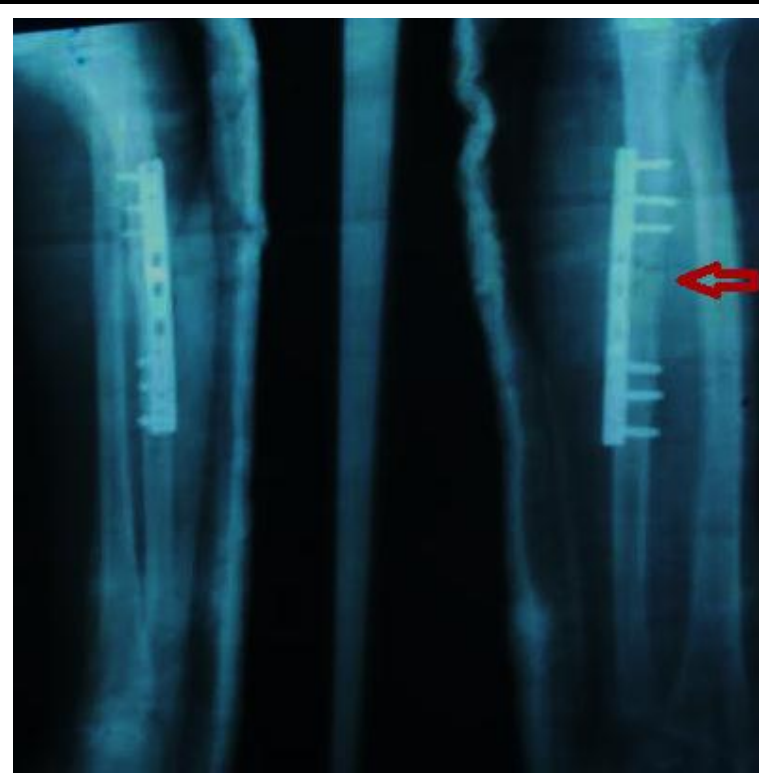

(a)

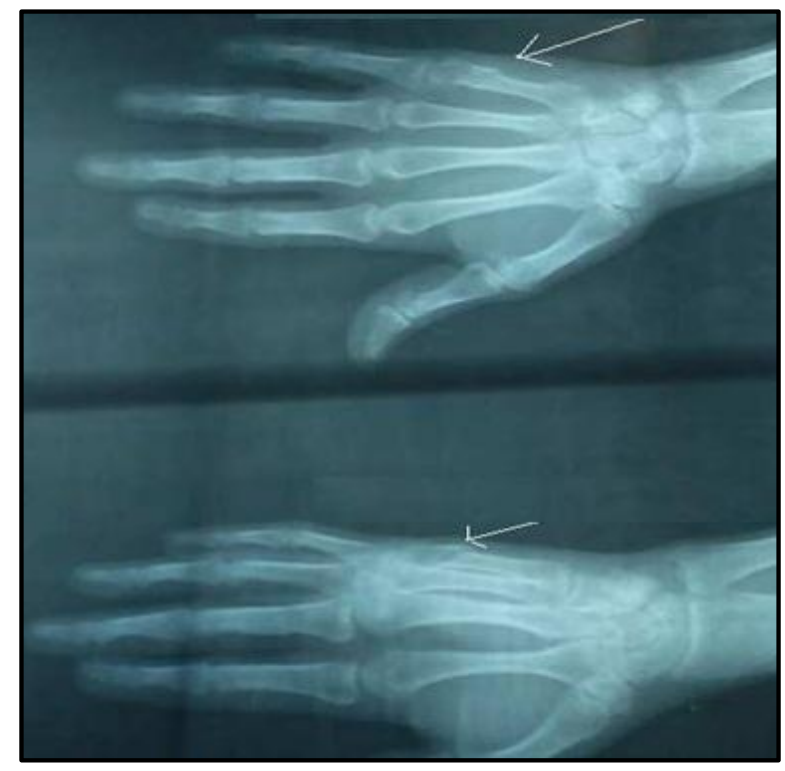

(B)

Figure 4: Left image shows antro-posterior and lateral views of plate of left ulna with plate and screws fixation (a) and right fifth metacarpal fracture (b). Red left image arrow shows site of nonunited bone graft. Right image arrows show site of fracture in right metacarpal bone of case (5).

\section{DISCUSSION}

Medicolegal malpractice is not a new issue worldwide-though underestimated- and even competent forensic practitioners commit mistakes. This may be due to shortage of adequate facilities or personnel, competent training and qualifications of forensic examiners or shortage of good quality control in performing autopsies. Although some autopsy standards are published globally like those of the Royal College of Pathologists (Guidelines on Autopsy Practice, 2002) and the National Association of Medical Examiners (Peterson and Clark, 2006); their recognition, adoption, and applications are still insufficient in many areas worldwide including Egypt. Both standards had focused on external and in situ examination, removal and dissection of head, neck, chest and abdominal viscera for signs of diseases, injuries or therapy. The incomplete autopsy could be implemented in exceptional circumstances to be clarified in the medicolegal report. In the present study, authors presented selected cases of forensic profession malpractice related to both postmortem autopsy in the first three cases and two other cases related to clinical forensic medicine malpractice.
In case (1), the injury was due to contact firearm injury from a bore 16 shotgun weapon that resulted in the entrance of all projectiles forcibly inside the body through the large inlet wound. This led to the absence of signs of near firing around inlet wound or the corresponding clothes hole, and a large exit wound which is unusual in that site with relatively low muzzle velocity weapon. In a tight contact wound, the skin forms a seal around the muzzle, preventing much escape of hot gas and soot, so that soiling and burning are minimal or absent. There was no spread of shots which were derived outward by the force of compressed gases to form a large exit, which rarely occurs in shot-gun injuries (Knight, 1998; Sakko and Knight, 2004). The forensic examiner ignored the laboratory detection of powder residues on the clothes of the victim. Besides, there were no signs of quarrel or resistance on the body of the victim. The evidence of trace blood stains with attempts of cleaning was found on the house door from inside. The pattern of blood distribution at the scene revealed the transfer of the body. Noteworthy, the weapon was found beside the victim who was hard to imagine in a case of homicide. Eyewitnesses opinions were discrepant that should not be relied upon when the forensic examiner drew 
his conclusion about the distance of firing. There was a complete lack of accused persons' examinations, who were arrested on the same day of the crime. He could have found any link with the crime as blood in clothes and shoes or under nails, signs of a quarrel in the form of abrasions or bruises, powder residues on the hands or clothes, finger or footprints at the scene or finger or DNA fingerprints on the gun. He did not appreciate that absence of signs of near firing is consistent with contact firearm injuries. As there are many variables associated with firearm wounds, however, it is essential for test firing to be performed wherever possible to deduce distance of firing (Sakko and Knight, 2015) which has been ignored. It was discovered later that the victim's nephew has mistakenly shot him during an attempt to get his shotgun out from his pocket. This was undertaken as self-defense to compact accused persons who failed to be linked to the scene of the crime by any means apart from testimony of witnesses. Therefore, the forensic medicine malpractice, in this case, is a mix of the profession related (technical) errors due to an inappropriate interpretation of autopsy data and Medicolegal system associated errors due to missing crime scene and accused men examinations.

In Case (2), doubts and suspicions arise regarding the identity of the unknown body and the extent of its conformity with the missing person descriptions through his photo and relatives, for many reasons. There was a contradiction in describing the distinctive features of the unidentified body that the forensic physician mentioned, the presence of a congenital hare lip while the relatives of the deceased did not specify that attribute, but they said he was missing or broken teeth in his upper jaw. It is, therefore, necessary to verify the identity of the unknown person who was found and buried by exhuming the body and re-examining it to make sure it matches the description stated by the relatives and his antemortem photos. The hare-lip mentioned may often accompany the cleft palate visible in the bones of the upper jaw even if the body had decomposed. In such cases where there is a suspicion in the body identity through traditional methods, DNA testing of bone samples might be necessary in such a case to establish the true identity of the missing person. Furthermore, what has been described in the forensic medical report, were localized signs around the mouth and nose. Those were in the form of linear laceration of the lips, as well as the presence of bloody froth, congestion of the lungs and stomach emptiness of water; all indicated that death did not result from drowning, but is likely has occurred as result of smothering. Therefore, the body must be re-examined to ascertain the identity of the deceased and the manner of death.

Case (3) displayed the forensic examiner conclusion that the victim was attacked in his bed while he was under the effect of a hypnotic drug without requesting any toxicological analysis of stomach contents or blood and/or organs. The presence of multiple deep cut wounds in different sides of the head and the presence of multiple deep cut wounds on the back of the right and left forearms and wrists did not coincide with the attack of an unconscious or hypnotized person. Such wounds indicated that the victim was alert and attempted to prevent chopper strikes through movement of his head in different directions and to protect his head by his arms and hands that led to the presence of these defense wounds. The absence of frank blood on the bed and the walls beside the bed in addition to the presence of blood stains in sites away from the bed as described earlier reflected the movement of the victim in the room during the attack. All indicate that he was conscious during the attack. This did not coincide with the police officer or forensic examiner conclusions.

An evaluation of misinterpretation to other medical specialties malpractice was presented in case (4). Malpractice occurs when a physician fails to follow the standards of his or her profession resulting in harm. The legal standard of care is defined traditionally as "the degree of care and skill that a physician of the same medical specialty would use under similar circumstances" (Domino et al, 2010). To establish a successful claim against the anesthesiologist, all needed to be proven is that the resulting injury characteristically would not occur in the absence of negligence, 
under the exclusive control of the anesthesiologist, and the anesthesiologist is put in the position of having to prove that he or she was not negligent (Cheney et al, 1989). Accordingly, in the present case there is an absence of the element of error in the behavior of the anesthetist because of the following:

1- Sterilization and disinfection for the injection site were performed in the lumber area following the universal principles of the profession through using sterile disposable syringes and other tools.

2- The pain and inflammation the patient suffered from two months after hemorrhoidectomy operation may result from blood born infection from an infected focus in the patient's body activated for reasons like the genetic susceptibility or impaired immunity and/or hyperemia at the site of operation.

3- It is scientifically proven that the negative sputum sample for tuberculosis does not exclude the diagnosis of previous spinal tuberculosis because pulmonary tuberculosis is not always associated with bone tuberculosis. Spinal tuberculosis is usually a result due to hematogenous spread of $\mathrm{M}$. Tuberculosis (TB) into the dense vasculature of the cancellous bone of the vertebral bodies. The primary infection site is either a pulmonary lesion or an infection of the genitourinary system (Schirmer et al., 2010). Spread occurs either via the arterial or the venous route. Genetic susceptibility to spinal tuberculosis has recently been suggested. The most reliable diagnostic test for TB is a skin test where a small injection of an extract of the TB bacterium, is made just below the inside forearm not just sputum sample for pulmonary $\mathrm{TB}$ diagnosis ordered by the forensic examiner (Grag et al., 2011).

4- Absence of all elements of medical responsibility in that case for involved surgeon and anesthetist, though the expert anesthetist opinion was not asked for through the forensic examiner which was vital for such a case.

In reviewing the case of suspected permanent infirmity (Case 5), under the original and established medical guidelines of the Forensic Medicine Authority in Egypt (El-Eraqy et al., 1992), the presence of metal plates and screws as foreign bodies in the limbs is considered as a permanent disability, even if the limb movement is normal. Therefore, in the absence of complete healing, limitation of movement and accompanying pain in addition to permanent fixation of fractures with plates and screws; all justify consideration of forearm injury as a permanent infirmity on the contrary to what has been decided by the forensic examiner.

\section{CONCLUSIONS}

To conclude, in postmortem cases discussed, failure of good estimation of firing distance in firearm injury alongside deficient request of supporting laboratory-related information and crime scene inspection were remarkable in the first case. In other two autopsy cases, failure of appreciation of benefits of complete autopsy with full relevant and essential toxicological and DNA analyses, have been ignored by the forensic medicine practitioner. The last clinical forensic medicine related cases indicted a failure to judge and interpret malpractice or infirmity issues in lights of the presented information. Upon that, authors have figured out that the principal defects observed in discussed cases were mostly related to inadequate expertise, training, and qualifications, of forensic medicine practitioners as well as lack of adoption of quality control and global standards for performing complete autopsies.

\section{RECOMMENDATIONS}

Matshes et al., (2011) reviewed an evidencebased approach to perform as complete and sufficient autopsy as possible through three forensic autopsy goals. Those included the statutory duty for documenting cause and manner of death, the creation of minimal dataset for the societal and governmental inquiry like documented evidence that determines nature of injury or disease, and maintenance of forensic practitioner competency through training, qualifications and enough facilities. In lights of those approaches, the Egyptian medicolegal system is still adopting those global standards and guidelines to a limited degree. Still, many deficient areas need to be fulfilled to decrease the incidence of forensic physician malpractice. First of all, increasing budget to 
recruit and train a sufficient number of forensic medical practitioners to compact high demands for at least 3-5 years full time training before being a specialist like many other medical professions worldwide. Learning state of the art and updated forensic medicine and related sciences techniques with continuing medical education are highly desirable. Well-equipped and good number of morgues in each governorate in Egypt is recommended as well, which should be connected with imminent toxicology, biology, histopathology and genetic laboratories (Du, 2017) alongside good imaging facilities and implementation of good quality assurance programs. Caring for the chain of custody on transferring body fluids or tissue samples for histopathology or other chemical analyses should be guaranteed to obtain the most information that aid justice establishment (Vernard, 2002; Abdelmaboud and Ali, 2012). Furthermore, good legislation for proper and sequential linking of forensic examiners with the crime scene and police investigations before performing autopsy will much benefit conclusions reached as teamwork rather than dealing with the case separately. To conclude, a magic triangle of good education, legislation, and organization, is a key of advancing the multidisciplinary forensic medicine profession under the current situation in Egypt in the face of the ever-changing ways of criminal acts and revolutionary advances in forensic sciences.

\section{CONFLICT OF INTEREST}

No conflict of interest was declared by authors.

\section{REFERENCES}

Abdelmaboud R., and Ali A.K. (2012).Forensic medicine in Egypt and its role in justice establishment between reality and expected. Law journal for legal and economic studies. Faculty of Law. Alexandria university. Special issue.14251435.(translated, text in Arabic).

Adams T., and Krutsinger J. (2000).Crime scene investigation; Prentice Hall: Upper Saddle River, NJ.

Cheney F.W., Posner K., Caplan R.A., and Ward R.J. (1989). Standard of care and anesthesia liability. JAMA. 261:1599-1603.

DiMaio D., and DiMaio, V.J. (2001). Forensic Pathology. Practical aspects of criminal and forensic investigations. CRC Press, Boca Raton, FL, p.592.

Domino K.B., Cammarata B. J., and James W. F. (2010).Manual on Professional Liability, The American society of anesthesiologists, 74 (8): 65.

Du M. (2017). Analysis of errors in forensic science. J Forensic Sci and Med, 3(3), 139.

El-Eraqy M. (1992).Forensic medicine between prosecution and defense.Dar Altebaa Alhaditha.p.681.(translated, text in Arabic).

Garg R.K., and Somvanshi D.S.(2011).Spinal tuberculosis. A review. J Spinal Cord Med;34(5):440-454.

Guidelines on Autopsy Practice (2002): Report of a Working Group of the Royal College of Pathologists.

Knight B.(1998). Lawyers guide to forensic medicine: Handbook for court and chambers, William Heinemann Medical Books LT D,London.p. 99.

Matshes E. W., Milroy C. M., Parai J. L., Sampson B., Reichard R. R., and Lew E. O. (2011). What is a Complete Autopsy?. Academic Forensic Pathology, 1(1), 2-7.

Moritz A.R.(1981).Classical mistakes in forensic pathology: Alan R. Moritz (American Journal of Clinical Pathology, 1956). Am J Forensic Med Pathol. Dec;2(4):299-308.

Peterson G.F. and Clark S.C. (2006).Forensic autopsy performance standards. Am J Forensic Med Pathol. Sep;27(3):200-25.

Pinheiro J. (2006). Introduction to Forensic Medicine and Pathology, Forensic anthropology and medicine: complementary sciences from recovery to cause of death. A. Schmitt, E. Cunha and J. Pinheiro (eds). Humana Press, Totowa, New Jersey, 2006. 13-37.

Saukko P. and Knight B. (2004). Knight's Forensic Pathology, $3^{\text {rd }}$ Edition. Abingdon, Oxon: CRC Press.

Saukko P. and Knight B. (2015). Knight's Forensic Pathology, $4^{\text {th }}$ Edition. bingdon, Oxon: CRC Press.

Schirmer P., Renault C.A., Holodniy M. (2010). Is spinal tuberculosis contagious? Int $\mathrm{J}$ Infect Dis; 14(8):e659-66

Vernard I.D. (2002).Medicolegal autopsies and Autopsy Toxicology. Handbook of autopsy practice, $3^{\text {rd }}$ Ed, Edited by J.Ludwig, Humana Press Inc, Totowa. NJ. 


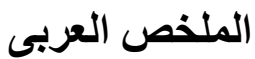

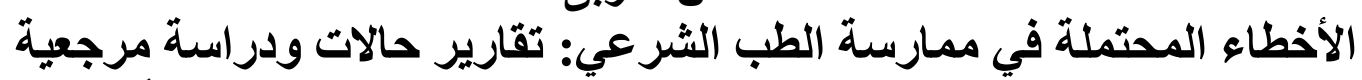

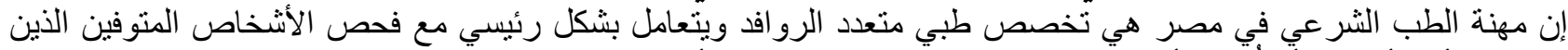

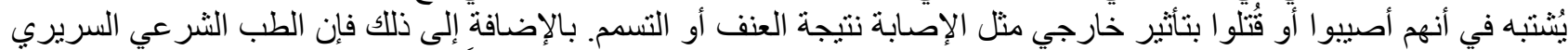

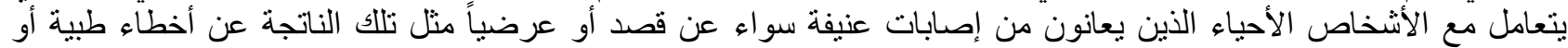

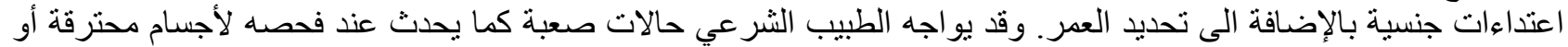

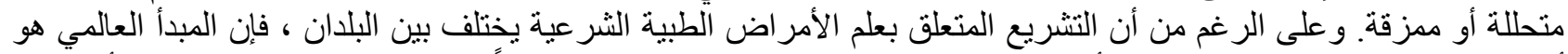

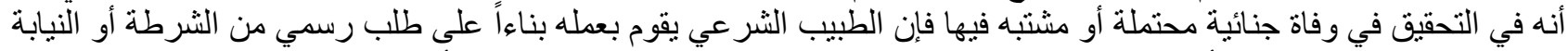

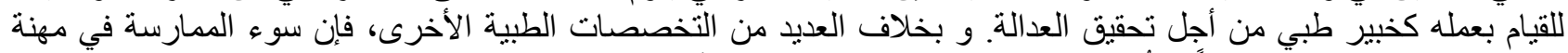

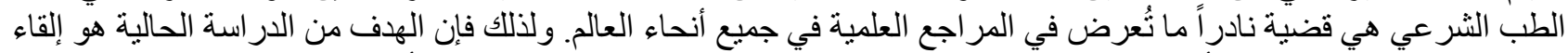

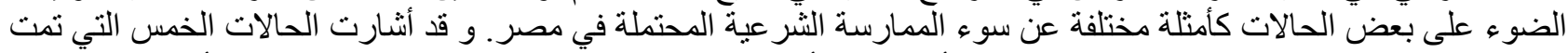

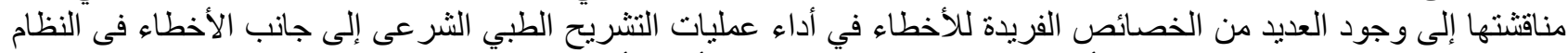

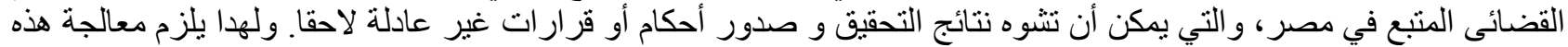

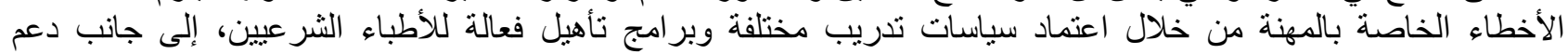
التشريعات وتوفير التمويل اللازم للتجهيز ات التكميلية. 